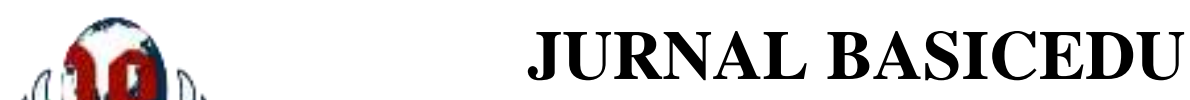

Volume 5 Nomor 5 Tahun 2021 Halaman 3858 - 3865

Research \& Learning in Elementary Education

https://jbasic.org/index.php/basicedu

\title{
Pembelajaran Model Blended Learning pada Mata Kuliah Sains Lanjut dengan Menggunakan Kurikulum KKNI
}

\author{
Tiara Nurhayati $^{1 凶}$, Mohamad Agung Rokhimawan ${ }^{2}$, Ragil Dian Purnama Putri $^{3}$ \\ Program Magister Pendidikan Guru Madrasah Ibtidaiyah UIN Sunan Kalijaga, Indonesia ${ }^{1,2,3}$ \\ E-mail: 20204081003@student.uin-suka.ac.id ${ }^{1}$, mohamad.rokhimawan@uin-suka.ac.id², \\ 20204081007@student.uin-suka.ac.id ${ }^{3}$
}

\begin{abstract}
Abstrak
Prodi PGSD tidak akan lepas tanpa adanya sebuah pembelajaran yang mengarah pada pendidikan di sekolah dasar termasuk mata kuliah Sains Lanjut. Adapun model pembelajaran yang dapat digunakan dalam pembelajaran Sains Lanjut ini yaitu model pembelajaran blended learning dengan menggunakan kurikulum KKNI. Tujuan dari artikel ini yaitu untuk mengetahui fakta dari pembelajaran model blended learning pada mata kuliah Sains Lanjut dengan menggunakan kurikulum KKNI. Metode dalam pengambilan data yaitu menggunakan metode kualitatif deskriptif. Adapun subjek penelitian yaitu kaprodi, dosen, dan perwakilan mahasiswa. Sedangkan objek penelitian yaitu segala sesuatu yang berkaitan tentang pembelajaran blanded learning pada Sains Lanjut di PGSD UAD dengan menggunakan kurikulum KKNI. Hasil dari penelitian ini yaitu adanya penerapan kurikulum KKNI di PGSD UAD sudah berjalan dengan baik sesuai dengan prosedur yang ada. Selain itu pembelajaran model blended learning pada Sains Lanjut juga sudah dijalankan oleh dosen maupun mahasiswa. Faktor pendukung dan penhgambat yang dialami dapat diatasi sesuai dengan kemampuan sehingga berjalannya pembelajaran yang lebih baik
\end{abstract}

Kata Kunci: Model Blended Learning, Sains Lanjut, Kurikulum KKNI.

\begin{abstract}
PGSD study program will not be separated without a learning that leads to education in elementary school including Advanced Science courses. The learning model that can be used in Advanced Science learning is a blended learning model using the KKNI curriculum. The purpose of this article is to find out the facts of blended learning model learning in Advanced Science courses using the KKNI curriculum. Method in data retrieval is using descriptive qualitative methods. The research subjects are kaprodi, lecturers, and student representatives. While the object of research is everything related to blanded learning in Advanced Science at PGSD UAD using the KKNI curriculum. The result of this study is that the implementation of the KKNI curriculum at PGSD UAD has been going well in accordance with existing procedures. In addition, blended learning model learning in Advanced Science has also been run by lecturers and students. Supporting and diversity factors experienced can be overcome in accordance with the ability so that better learning runs.
\end{abstract}

Keywords: Blended Learning Model, Advanced Science, KKNI Curriculum.

Copyright (c) 2021 Tiara Nurhayati, Mohamad Agung Rokhimawan, Ragil Dian Purnama Putri

Corresponding author :

Email:20204081003@student.uin-suka.ac.id

DOI : https://doi.org/10.31004/basicedu.v5i5.1396

ISSN 2580-3735 (Media Cetak)

ISSN 2580-1147 (Media Online)

Jurnal Basicedu Vol 5 No 5 Tahun 2021

p-ISSN 2580-3735 e-ISSN 2580-1147 
3859 Pembelajaran Model Blended Learning pada Mata Kuliah Sains Lanjut dengan Menggunakan Kurikulum KKNI - Tiara Nurhayati, Mohamad Agung Rokhimawan, Ragil Dian Purnama Putri DOI: https://doi.org/10.31004/basicedu.v5i5.1396

\section{PENDAHULUAN}

Pada jurusan PGSD tentu mempelajari segala sesuatu yang berkaitan dengan pelajaran sekolah termasuk mata kuliah Sains Lanjut. Sains Lanjut dapat mempelajari dari berbagai kejadian serta segala sesuatu yang berkaitan dengan alam. Mata kuliah ini lebih menekankan pada konsep dasar Sains dari berbagai sumber diantaranya yaitu biologi, fisika, dan kimia. Tujuan pembelajaran Sains Lanjut diarahkan pada pemahaman konsep lebih dalam dan melatih sikap, penguasaan pengetahuan, keterampilan umum, dan keterampilan khusus. Tujuan yang akan dicapai dapat terpenuhi melalui berbagai alat maupun bahan dalam proses pembelajaran. Adanya bahan ajar maupun alat bantu lainnya dapat mempermudah pendidik dalam menyampaikan materi. Adapun fungsi dari bahan ajar sendiri yaitu dapat menyampaikan materi atau pesan dalam pembelajaran (Hamalik 2012). Secara umum, bahan ajar dapat digunakan sebatgai alat dalam menjelaskan materi pembelajaran. Selain itu, bahan ajar juga dapat dijadikan sebagai sumber dalam memecahkan masalah bagi mahasiswa yang turut mempelajari (Sudjana 2016).

Ada banyak faktor yang dapat mempengaruhi sumber kualitas dalam pembelajaran seperti kualitas pendidikan, (Fattah 2008). Salah satu kualitas pendidikan yaitu adanya bahan ajar yang memadai untuk mahasiswa. Bahan ajar dapat diartikan sebagai salah satu komponen pembelajaran yang harus disediakan. Hal tersebut karena berpedoman untuk proses pada pembelajaran sebagai kompetensi yang dapat disampaikan kepada mahasiswa (Ahmadi 2010). Adanya bahan ajar tentu dapat membantu program pembelajaran dalam melaksanakan pembelajaran yang terprogram. Maksudnya yaitu dapat melaksanakan pembelajaran yang jelas dan mahasiswa merasa terbantu dengan adanya pengemabangan bahan ajar. Bahan ajar dapat dikembangkan oleh pendidik atau dosen yang bermanfaat bagi proses pembelajaran. Bahan ajar ini dapat berupa modul digital, karena mengingat saat ini sudah dituntut untuk menggunakan model pembelajaran blended learning.

Adapun mata kuliah terkena imbas pada pembelajaran blended learning yaitu Sains Lanjut di prodi PGSD. Dimana mahasiswa didorong agar bisa beradaptasi terhadap pembelajaran blended learning dan menyebabkan prodi pendidikan guru lainnya. Pada saat mahasiswa menyelesaikan study yang mereka alami semakin berkembangnya secara cepat, maka dari hasil wawancara kami terhadap dosen berkeinginan merubah sistem pengajaran menjadi lebih inovatif terhadap mata kuliah yang beliau ampu yang tadinya pembelajaran sering tatap muka, lalu berubah menjadi daring (online). Tetapi dengan adanya blended learning ini memudahkan dalam pembelajaran dari segi aspek manapun baik penyampaian, model pembelajaran, gaya pembelajaran, serta media pembelajaran. Ada model pembelajaran yang cocok lingkup pendidikan menurut beberapa peneliti, model tersenut ialah ): (1) Driver face to face-pendidik memberitahu secara langsung serta menambah alat digital, (2) Rotasi- peserta didik melaksanakan belajar online sendiri serta waktu di ruang kelas bertemu secara langsung, (3) Flex- kurikulum diajarakan menggunakan platform digital serta guru menerima konsultasi, (4) Labs - Seluruh kurikulum diajarkan menggunakan platform digital dengan tempat fisik konsisten, biasanya di ruang kelas ini menggunakan model tradisional, (5) Self-blend - peserta didik menambah pelajaran tradisional ke bimbel via online, (6) Pengemudi daring - peserta didik selesaikan semua bimbel dengan platform online, (Oliver \& Trigwell, 2005).

Problem terjadi pada akademik saat ini dalam mencari titik temu dari permasalahan menyukseskan pendidikan untuk mencetak generasi bangsa yang unggul dan berpengetahuan luas (Abdul 2012). Berbagai macam tahap pada saat proses belajar dilaksanakan pendidik serta peserta didik untuk menunjang peningkatan hasil belajar di ruang belajar. Pendidikan dengan mutu yang bagus ialah pendidikan berpedoman 4 pilar sebagai berikut: (1) learning to know yaitu pembelajaran memperoleh ilmu pengetahuan serta berikutnya learning to learn, (2) learning to do merupakan pembelajaran mendapatkan teknik dasar tentang suasana serta kelompok kerja berbeda, (3) learning to live together ialah pembelajaran memberi apresiasi serta menerapkan situasi saling bergantung, beraneka ragam, tidak egois, serta berdamai, (4) learning to be yaitu pembelajaran 
3860 Pembelajaran Model Blended Learning pada Mata Kuliah Sains Lanjut dengan Menggunakan Kurikulum KKNI - Tiara Nurhayati, Mohamad Agung Rokhimawan, Ragil Dian Purnama Putri DOI: https://doi.org/10.31004/basicedu.v5i5.1396

mendorong individu terhadap sifat pribadinya dalam tanggung jawab terhadap diri sendiri, menjadi bangsa negara dan hamba Allah swt. seutuhnya (Moh.Surya 1997).

Dalam melakukan pembelajaran Sains Lanjut ini menerapkan pembelajaran menggunakan model blended learning pada kurikulum KKNI di prodi PGSD. Kurikulum berbasis KKNI yang digunakan pada PGSD UAD telah memberikan melaksanakan kurikulum KKNI pada jenjang S1 atau sarjana. Hal tersebut dapat dilihat dari learning outcomes yang terdapat pada kurikulum berbasis KKNI. Dalam pelaksanaan telah diharapkan dapat memberikan luaran yang terbaik mampu dalam menghadapi masalah maupun menganalisis masalah sampai pada memecahkannya. (Masnun and Arifuddin 2018). Selain itu, dengan adanya tekhnologi informasi pada proyek kelas hubungan interaksi dan komunikasi mahasiswa meningkat serta mahasiswa bisa evaluasi pemahaman tentang materi (Alexander 2010).

Perguruan tinggi adalah satuan pendidikan tertinggi yang memiliki tanggung jawab dan tugas untuk menghasilkan sumber daya manusia yang berdaya saing tinggi. Daya saing yang dimaskud yaitu guna menciptakan luaran yang bisa bersaing dalam nasional maupun internasional. Hal tersebut sesuai dengan acuan dan prinsip adanya kurikulum KKNI (Maslahah 2018). Kurikulum KKNI ini mengasah potensi mahasiswa dalam memiliki kompetensi yang lebih luas dan memiliki kemampuan sesuai yang diperlukan pada pasaran maupun masyarakat. Adanya kurikulum KKNI juga dapat memudahkan pada perguruan tinggi dalam menentukan tujuan hasil dari capaian mahasiswa selama melaksanakan proses pembelajaran. Sehingga, model blended learning pada kurikulum KKNI ini berkesinambungan dalam proses pencapaian hasil terhadap mahasiswa dalam mencetak mahasiswa lebih inovatif, kreatif, serta memiliki wawasan dan ilmu yang sesuai zamannya. Dalam memenuhi kebutuhan menciptakan lulusan yang memiliki daya saingbaik pada ruang lingkup nasional maupun internasional (Masykur, dkk, 2018). Adapun penelitian terdahulu telah ditemukan adanya kesulitan dalam menyusun kurikulum berbasis KKNI. Kesulitan tersebut yaitu adanya tuntutan dari masyarakat yang perlu adanya evaluasi kembali dan peninjauan (Casmini 2014).

Implementasi kurikulum KKNI juga telah memberikan hasil lulusan pada program studi PGSD yang terbaik. Hal yang dapat didapat mahasiswa yaitu dapat menyusun berdasarkan dengan kebutuhan dan kompetensi yang telah dilaksanakan prodi (Hasanah 2014). Pelaksanaan kurikulum KKNI pada prodi PGSD UAD pada studi pendahuluan yang sudah dilaksanakan sejauh ini sudah terlaksana dengan pilar yang sesuai. Dalam mengorganisasikan sumber dayanya juga sudah dalam kurikulum dan interpretasi kurikulum KKNI. Pendapat ahli Loucks dan Lieberen dalam mengimplemntasikan kurikulum di perguruan tinggi harus danya praktik yang nyata, karena hal tersebut akan membawa kualitas luaran mahasiswa. (Azmi 2019). Hal yang sudah disebutkan tersebut telah mengandung implikasi bahwa perlu adanya penelitian lebih dalam lagi mengenai pembelajaran model blended learning pada mata kuliah Sains Lanjut dengan menggunakan kurikulum KKNI. Data dan fakta yang akan didapatkan akan menjadi bahan masukan maupun saran akan tercapainya sebuah pembelajaran Sains Lanjut dengen model pembelajaran blended learning yang lebih baik lagi.

\section{METODE PENELITIAN}

Pendekatan kualitatif dengan metode deskriptif dapat digunakan untuk melakukan penelitian pada pembelajaran blanded learning mata kuliah Sains Lanjut. Penelitian ini melihat fenomena nyata di lapangan yang dialami oleh subjek dalam penelitian dengan menuliskan menggunakan bahasa ilmiah, (Moleong 2017). Jenis penelitian pada pendekatan kualitatif yang digunakan yaitu digunakan dalam memperoleh data ataupun informasi. Sedangkan subjek penelitian meliputi ketua prodi PGSD UAD sebagai penanggung jawab pembelajaran, dosen Sains Lanjut sebagai pengampu kelas, dan perwakilan mahasiswa berjumlah 2 orang. Objek dari penelitian ini yaitu berupa semua yang bersangkutan dengan pembelajaran blanded learning mata kuliah Sains Lanjut. Pengumpulan data dengan menggunakan beberapa teknik. Teknik dalam mengumpulkan 
3861 Pembelajaran Model Blended Learning pada Mata Kuliah Sains Lanjut dengan Menggunakan Kurikulum KKNI - Tiara Nurhayati, Mohamad Agung Rokhimawan, Ragil Dian Purnama Putri DOI: https://doi.org/10.31004/basicedu.v5i5.1396

data menggunakan observasi, wawancara, maupun dokumentasi, (Sugiyono 2014). Metode ini digunakan untuk mendeskripsikan dengan objektif fakta yang terjadi di PGSD UAD. Adapun caranya yaitu melakukan proses analisis menggunakan pengumpulan data di lapangan, reduksi, penyajian, dan menarik kesimpulan.

\section{HASIL DAN PEMBAHASAN}

\section{Kurikulum KKNI}

Mustahil jika suatu institusi pendidikan tidak mempunyai kurikulum, karena kurikulum adalah pusat dari sistem pembelajaran. Tanpa adanya kurikulum maka proses dalam pembelajaran tidak akan terarah. Jika kurikulum diartikan secara yaitu keseluruhan pengetahuan dan segala sesuatu yang dapat ditransformasikan ke dalam pendidikan sehingga dapat meningkatkan perkembangan yang lebih baik dalam membentuk kepribadian seseorang (Al-Jabburi, Jasim, and As-Sulthani 2013).

Pada tanggal 17 Januari 2012 telah keluar Peraturan Presiden Nomor 8 Tahun 2012 tentang Kerangka Kualifikasi Nasional Indonesia (KKNI). Kurikulum KKNI ini tentu memberikan dampak agar lulusan dapat menjadi lebih memiliki kualifikasi pendidikan yang baik dalam menambah pengalaman kerja. KKNI ini juga memiliki persamaan dengan kurikulum KBK pada sebelumnya, hanya saja KKNI lebih lebih deskripsi dalam menentukan lulusan dari berbagai tingkat. KKNI juga disiapkan untuk mencapai capaian pembelajaran atau learning outcame (LO) (Suwadi 2016).

Saat ini prodi PGSD UAD sudah menerapkan kurikulum KKNI dengan tujuan agar lulusan mahasiswa nantinya memiliki bekal yang lebih baik. Adapun capaian pembelajaran tersebut yaitu melalui pembelajaran pengetahuan, sikap, maupun keterampilan. Penyusunan kurikulum KKNI di PGSD UAD tentu mencapai pada prinsip-prinsip yang ada dalam penyelenggaraan kurikulum KKNI (Setiawan 2016). Hal tersebut dilakukan dengan tujuan agar nantinya lulusi PGSD UAD dapat bersaing dan menjadi mahasiswa yang berkualitas (Ibtida and MI 2019). Pada pengaplikasian kurikulum KKNI tidak lepas adanya acuan yang digunakan. Adapaun acuan tersebut yaitu, (a) dapat mendesain program yang lebih rinci, (b) adanya program sesuai dengan struktur yang jelas, (c) membuat jadwa yang digunakan untuk memonitoring dalam melakukan Tindakan yang baik, (Solichin 2021).

Seluruh pelaksanaan kurikulum serta pembelajaran dapat dijelaskan dari platform digital serta pertemuan secara langsung terjadwal. Perlu digaris besar bawah banyak model serta banyak cara dalam penyampaian. Beberapa macam pembelajaran terdiri dari e-learning, seminar online, serta media dan acara lainnya. Contohnya facebook, e-mail, blog, twitter, dan media sosial lainnya. blended learning jauh lebih efektif dan efesien sehingga mampu mencetak hasil mahasiswa dari kelas biasanya. Dengan menggunakan model tatap muka dikombinasi dengan daring membuka peluang guru memberikan perhatian. Sehingga guru sekarang memfokuskan mengembangkan potensis mahasiswa untuk dikembangkan lagi. Pendukung pembelajaran tekhnologi melalui online disebut asynchronous dengan memfasilitasi mahasiswa seperti kuota serta media pembelajaran lainnya yang mahasiswa bisa akses (Solikhah 2015).

\section{Pembelajaran Blanded Learning pada Sains Lanjut dengan Kurikulum KKNI}

Blended learning ialah kalimat sering dipergunakan sebagai model pembelajaran pada penerapan pembelajaran dilaksanakan dengan mengkombinasikan pembelajaran konvensional serta pembelajaran melalui tekhnologi informasi dan komunikasi (Thorne 2003). Blended learning dipergunakan sebagai penjelas dari berbagai konteks pembelajaran dengan mengkombinasikan pembelajaran teknologi informasi dan komunikasi dengan pembelajaran daring, mengembangkan kompetensi di perguruan tinggi (Purwaningsih 2009). Bahasan lebih dalam Purwaningsih menjabarkan menonjolnya dari pendidikan tinggi ialah menggunakan kombinasi terhadap pembelajaran tatap muka serta pembelajaran online. Aturan akademik berbagai perguruan tinggi dengan syarat pembelajaran secara tatap muka dan bertemu menyebabkan 
3862 Pembelajaran Model Blended Learning pada Mata Kuliah Sains Lanjut dengan Menggunakan Kurikulum KKNI - Tiara Nurhayati, Mohamad Agung Rokhimawan, Ragil Dian Purnama Putri DOI: https://doi.org/10.31004/basicedu.v5i5.1396

pembelajaran e-learning semudah itu digantikan oleh pembelajaran konvensional atau bertemu. Dari hasil penelitia lapangan terhadap narasumber melalui aplikasi komunikasi pembelajaran blended learning dari indikator absensi mahasiswa di kelas, keaktifan mahasiswa dalam mengikuti perkuliahan, diskusi, memberikan pertanyaan, memberikan tanggapan serta respon pada proses pembelajaran di kelas. Adapun dampak yang signifikan dari penerapan pembelajaran blended learning pada motivasi belajar mahasiswa. Terlihat dari tingkat absensi kehadiran mahasiswa di kelas mencapai $80 \%$. Kegiatan mahasiswa pun bukan dari kehadiran, akan tetapi peningkatan interaksi sosial antara mahasiswa dengan dosen atau sebaliknya. Barulah pembelajaran blended learning mahasiswa lebih antusias pada saat bertanya, memberikan tanggapan permasalahan yang di bahas, mencoba memberikan jawaban dari pertanyaan teman, melakukan diskusi terhadap tema-tema terkait dengan perkuliahan khususnya mata kuliah sains lanjut. Pada saat mata kuliah sains lanjut berlansung peserta didik dapat mengikuti dengan baik. Sebagai mana diungkapkan oleh ibu Siwi pada saat wawancara sebagai berikut:

"Antusias mahasiswa dalam pembelajaran blended learning sangat tinggi, karena fleksibel jadi tidak terpaku sama tempat."

Tidak ada perubahan yang signifikan terhadap belajar dengan metode konvensional beralih ke blended learning sehingga mutu pembelajaran melalui blended learning dampaknya masih sangat baik, seperti yang di ungkapkan oleh bapak ragil sebagai berikut

"Mutu mahasiswa lebih baik tidak terlalu buruk, karena masih bisa mengikuti pembelajaran. Hal tersebut sambil Ibu pantau ketika pembelajaran berlangsung."

Selain itu perbedaan yang dirasakan dari belajar tatap muka menjadi blended learning itu yang dirasakan oleh mahasiswa sebagai berikut:

"Iya tentunya ada, diantaranya yaitu sosial jadi berkurang, komunikasi antar teman sejawat menjadi berbeda topik, serta banyak anak yang juga melewatkan beberapa mata kuliah yang harusnya praktikum kita hanya melihat dosen menayangkan video tutorial praktikum sesuai materi. Tetapi senang menjalaninya, karena semester itu dalam belajar Sains Lanjut tergantung kita bagaimana cara menerima pembelajaran dan memposisikan diri bahwa pembelajaran blended learning juga baik untuk dilaksanakan."

Sehingga model blended learning ini sesuai dengan tujuan pembelajaran yang ingin tercapai, aktivitas pembelajaran yang relevan, dan dapat menentukan relevan tidaknya terhadap pembelajaran konvensional serta aktivitas apa yang relevan terhadap online learning. Blended learning pada pembelajaran sains lanjut pada kurikulum kkni ini dapat mengatasi permasalahan pembelajaran pada perguruan tinggi, serta tidak adanya penurunan mutu pada mahasiswa. Proses belajar pada mahasiswa pun menjadi fleksibel dengan adanya blended learning ini dan terkhusus pada masa sekarang. Interaksi antar dosen dan mahasiswa pada pembelajaran sains lanjut pun berjalan sesuai RPS.

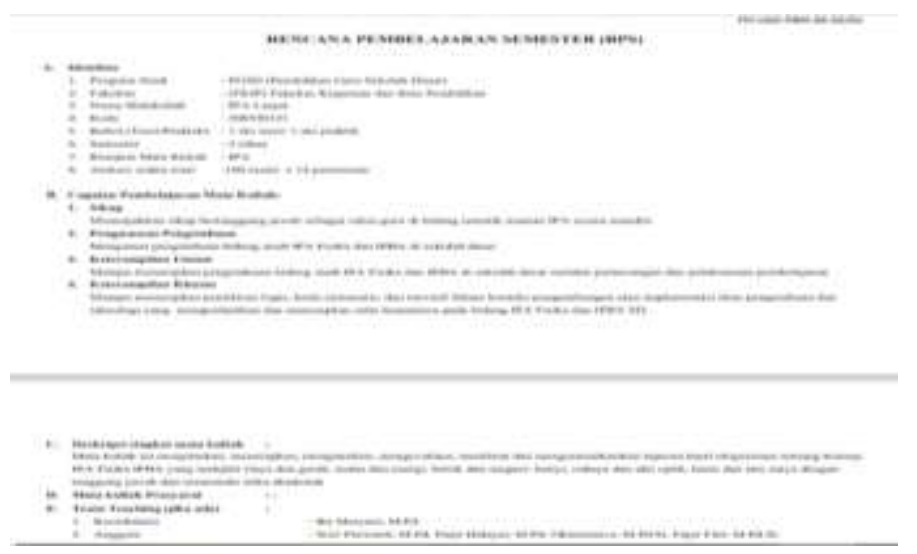

Gambar 1. RPS Mata kuliah Sains Lanjut 
3863 Pembelajaran Model Blended Learning pada Mata Kuliah Sains Lanjut dengan Menggunakan Kurikulum KKNI - Tiara Nurhayati, Mohamad Agung Rokhimawan, Ragil Dian Purnama Putri

DOI: https://doi.org/10.31004/basicedu.v5i5.1396

\section{Dampak adanya Pembelajaran Blended Learning pada Sains Lanjut}

Jika dilihat dari Kerangka Kualifikasi Nasional Indonesia (KKNI), satu SKS merupakan 50 menit tatap muka, 50 menit tugas mandiri dan 50 menit tugas tersusun, Sehingga belended learning ialah solusinya. 50 menit face to face, dan 100 menit menggunakan online sistem. Blended learning dapat memberikan jawaban dengan cara pengaplikasian pembelajaran era digital ini. Kemajun tekhnologi digital mencetak interaksi antar manusia. Jaringan internet semakin bagus serta infrastruktur tekhnologi memudahkan interaksi perorangan. Lingkup komunikasi menjadi terbuka. Interaksi yang terjadi pada pembelajaran sains pun semakin hidup dan aktif antar mahasiswa dengan mahasiswa atau mahasiswa dengan dosen. Pembelajaran melalui blended learning dapat lebih kreatif inovatif disampaikan, strategi dan metode yang digunakan dosen pun jauh lebih menarik dengan menyesuakan kemampuan mahasiswa dengan adanya blended learning. Dengan demikian pembelajaran sains lanjut dengan blended learning ini dapat meningkatkan hasil pembelajaran yang lebih terarah sesuai dengan kurikulum serta sistem pembelajarannya dapat mencapai pada tujuan yang sesuai. Tidak hanya itu prestasi yang diraihpun tidak kalah menarik dengan masih penerapan pembelajaran konvensional saja. Bisa di lihat dari gambar dibawah ini.

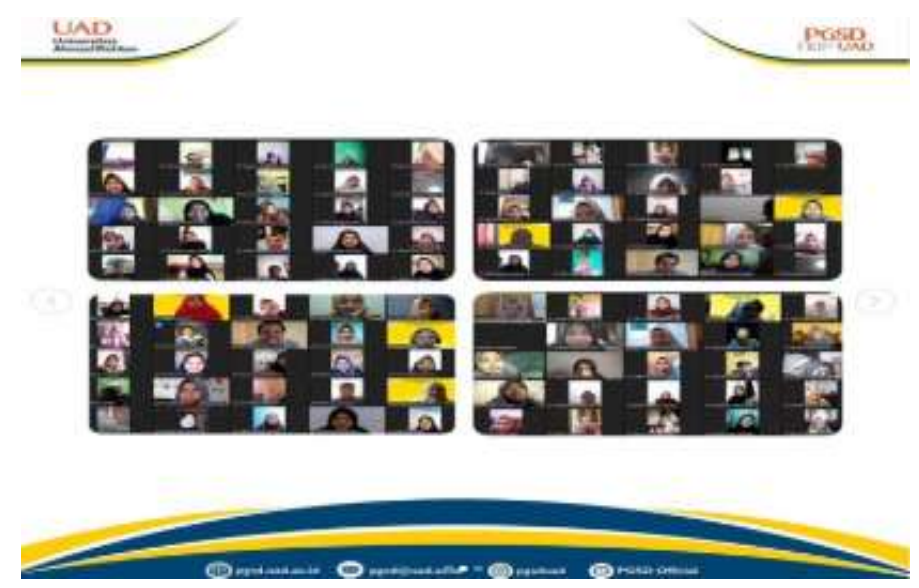

\section{Gambar 2. Proses Pembelajaran Sains Lanjut yang Menggunakan Blended Learning}
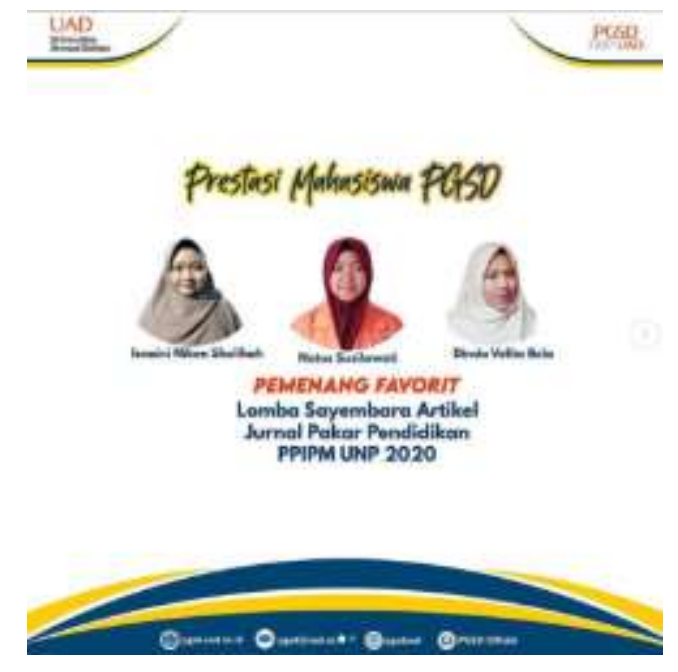

Gambar 3. Prestasi yang Di Raih 
3864 Pembelajaran Model Blended Learning pada Mata Kuliah Sains Lanjut dengan Menggunakan Kurikulum KKNI - Tiara Nurhayati, Mohamad Agung Rokhimawan, Ragil Dian Purnama Putri DOI: https://doi.org/10.31004/basicedu.v5i5.1396

\section{KESIMPULAN}

Prodi PGSD tidak akan lepas tanpa adanya sebuah pembelajaran yang mengarah pada pendidikan di sekolah dasar termasuk mata kuliah Sains Lanjut. Adapun model pembelajaran digunakan pada pembelajaran Sains Lanjut ini yaitu model pembelajaran blended learning dengan menggunakan kurikulum KKNI. Dengan adanya peningkatan motivasi belajar mahasiswa terhadap penerapan model blended learning pada mata kuliah Sains Lanjut pada jurusan PGSD UAD yang ditunjukkan oleh keaktifan dan partisipasi mahasiswa, frekuensi belajar dan keaktifan mahasiswa dalam diskusi, bertanya dan memberikan masukan. Hasil dari penelitian ini yaitu adanya penerapan kurikulum KKNI di PGSD UAD sudah berjalan dengan baik sesuai dengan prosedur yang ada. Selain itu pembelajaran model blended learning pada Sains Lanjut juga sudah dijalankan oleh dosen maupun mahasiswa. Faktor pendukung dan penhgambat yang dialami dapat diatasi sesuai dengan kemampuan sehingga berjalannya pembelajaran yang lebih baik.

\section{UCAPAN TERIMA KASIH}

1. Terima kasih kepada prodi Pendidikan Guru Sekolah Dasar Universitas Ahmad Dahlan yang telah membantu dan mensuport penelitian ini.

2. Terima kasih kepada program Pascasarjana Pendidikan Guru madrasah Ibtidaiyah UIN Sunan kalijaga yang telah mensuport adanya penelitian ini.

3. Terima kasih kepada seluruh informan yang turut membantu dalam memberikan informasi sedetail mungkin.

\section{DAFTAR PUSTAKA}

Abdul, Majid. 2012. "Perencanaan Pembelajaran." Bandung: Rosda Karya.

Ahmadi, Ahmad. 2010. Ilmu Pendidikan. Jakarta: Rineka Cipta.

Al-Jabburi, Imran Jasim, And Hamzah Hasyim As-Sulthani. 2013. "Al-Manahij Wa Thara'iq Tadris AlLughah Al-"Arabiyyah.” 'Amman: Muassasah Dar Ash-Shadiq Ats-Tsaqafiyyah.

Alexander, S. 2010. "Flexible Learning In Higher Education." International Enclopedia Of Education 44147.

Azmi, Ulil. 2019. "Kurikulum Program Studi Manajemen Pendidikan Islam Berbasis Kkni Dalam Keterserapan Lulusan Pada Dunia Kerja." Nizāmulilmi: Jurnal Manajemen Pendidikan Islam 4(01):80110.

Casmini, Casmini. 2014. "Evaluasi Dan Peninjauan Kurikulum Bki Berbasis Kkni." Hisbah: Jurnal Bimbingan Konseling Dan Dakwah Islam 11(1):125-44.

Fattah, Nanang. 2008. "Pembiayaan Pendidikan: Landasan Teori Dan Studi Empiris." Jurnal Pendidikan Dasar 1.

Hamalik, Oemar. 2012. Kurikulum Dan Pembelajaran. Jakarta: Bumi Aksara.

Hasanah, Nur. 2014. "Kesiapan Perguruan Tinggi Dalam Menerapkan Kurikulum Berbasis Kkni (Studi Kasus Di Fakultas Tarbiyah Dan Keguruan Iain Ambon)." Jurnal Fikratuna 6(2).

Ibtida, Al, And Mi. 2019. "Analyzing Madrasah Ibtidaiyah Teacher Candidates Skill Of Technological Pedagogical Content Knowledge On Natural Science Learning.” Jurnal Pendidikan Guru.

Maslahah, Any Umy. 2018. "Penerapan Kurikulum Mengacu Kkni Dan Implikasinya Terhadap Kualitas Pendidikan Di Ptkin." Edukasia: Jurnal Penelitian Pendidikan Islam 13(1):227-48.

Masnun, Moh. Maufur Syaibli, And Ahmad Arifuddin. 2018. "Respon Stakeholders Terhadap Kurikulum 
3865 Pembelajaran Model Blended Learning pada Mata Kuliah Sains Lanjut dengan Menggunakan Kurikulum KKNI - Tiara Nurhayati, Mohamad Agung Rokhimawan, Ragil Dian Purnama Putri DOI: https://doi.org/10.31004/basicedu.v5i5.1396

Berbasis Kerangka Kualifikasi Nasional Indonesia (Kkni) Jurusan Pgmi Iain Syekh Nurjati Cirebon.” Al Ibtida: Jurnal Pendidikan Guru Mi 5(1):25-38.

Masykur, Ruhban, Undang Rosidin, And Agung M. Iqbal. 2018. "Implementasi Kurikulum Kkni Pada Program Studi Matematika Universitas Islam Negeri Raden Intan Lampung." Numerical: Jurnal Matematika Dan Pendidikan Matematika 7-12.

Moh.Surya. 1997. "Psikologi Pembelajaran Dan Pengajaran.” Bandung: Ppb-Ikip Bandung.

Moleong. 2017. Metode Penelitian Kualitatif. Bandung: Remaja Rosdakarya.

Oliver, M., And K. Trigwell. 2005. “Can 'Blended Learning’ Be Redeemed?".” E-Learning 2(1):17-26.

Purwaningsih, W. 2009. "Identifikasi Kesulitan Pembelajaran Bioteknologi Pada Guru." Sekolah Pascasarjana Universitas Pendidikan Indonesia, Bandung.

Setiawan, Deny. 2016. "Ilmu-Ilmu Sosial Membentuk Karakter Bangsa Dalam Rangka Daya Saing Global." In Seminar Nasional Pendidikan. Makassar: Unm.

Solichin, Wahab Abdul. 2021. "Analisis Kebijakan: Dari Formulasi Ke Penyusunan Model-Model Implementasi Kebijakan Publik.” Bandung: Bumi Aksara.

Solikhah, Imroatus. 2015. "Kkni Dalam Kurikulum Berbasis Learning Outcomes. Lingua.” Jurnal Bahasa, Sastra, Dan Pengajarannya, 12(1).

Sudjana, Nana. 2016. "Penilaian Hasil Proses Belajar Mengajar.” Bandung: Rosdikarya.

Sugiyono. 2014. Metode Penelitian Pendidikan Pendekatan Kuantitatif, Kualitatif, Dan $R$ \& D. Bandung: Alfabeta.

Suwadi. 2016. "Pengembangan Kurikulum Pendidikan Agama Islam Pada Pendidikan Tinggi Mengacu KkniSnpt Berparadigma Integrasi-Interkoneksi Di Program Studi Pai Fitk Uin Sunan Kalijaga Yogyakarta." Jurnal Pendidikan Agama Islam 2.

Thorne, K. 2003. "Bleanded Learning, How To Integrate Online And Traditional Learning.” Uk: Kogan Page. 